\title{
Peculiarities of ultra-sound dispersion of thermally expanded graphite
}

\author{
C Nadezhda V. Pykhova, ${ }^{1+}$ Nikolay V. Negutorov,${ }^{2}{ }^{+}$ \\ Anastasia N. Zhanakhova, ${ }^{3}$ and Alexandre Yu. Prutskov ${ }^{2}$ \\ ${ }^{1}$ Department of Chemical Technology and Computational Chemistry. Chelyabinsk State University. \\ Molodogvardeytsev St., 70b. Chelyabinsk, 454021. Russia. \\ Phone: +7 (351) 799-70-66.E-mail:pihovanv@yandex.ru \\ ${ }^{2}$ Department of Combat Employment of Automated Control Systems, Branch of Military \\ Educational and Scientific Centre of Air Forces "Air Force Academy named after Professor \\ N.E. Zhukovsky and Y.A. Gagarin Gagarin (MESC of AF "AFA") in the city of Chelyabinsk. Russia. \\ ${ }^{3}$ Department of Chemical Technology National Research South-Ural State University. \\ Pr. Lenina, 76. Chelyabinsk, 454080. Russia. Phone: +7 (351) 267-95-70.
}

\begin{abstract}
*Supervising author; ${ }^{+}$Corresponding author
Keywords: natural graphite, thermally expanded graphite, dispersed graphite, breakage of graphite, liquids' polarity, wettability, erosion activity, ultra-sound dispersion, cavitation, nano-dimensional plates, X-ray spectral micro-chemical analysis, crystal-like structure, BET method.
\end{abstract}

Abstract
Thermally expanded graphite (TEG) is one of the best precursors for receiving of plane nanodimensional particles. Crucible graphite of Taigin deposit was used as a basic material to receive TEG. It is established that repeated thermo-chemical, as well as additional mechanical TEG dispersion does not lead to formation of nano-dimensional graphite particles. In order to receive graphite particles with several nanometers of thickness, TEG was treated by ultra-sound dispersion in four liquid mediums. Different influence of chosen liquid mediums on the process of ultra-sound dispersion of TEG particles is conditioned by peculiarities of liquids' behavior in cavitation process, it is described integrally by a notion "erosion activity". Erosion activity, in the first turn, depends on the superficial tension. The quantity of the received broken material is defined by the depth of penetration of the liquid into the body volume, which depends on liquid wettability. The used liquids: water, acetone, benzene and toluene had different polarity and superficial tension that allowed to put into reality different physical and chemical effects at TEG dispersion. Benzene has the lowest meaning of superficial tension, it moistens the graphite surface very well and penetrates easily into its micropores. Despite of the relatively low erosion capacity, non-polar organic liquids, penetrating to the big depth into the graphite particle's volume are capable to provoke a visible breaking influence at ultra-sound dispersion on inner graphite structures and its breakage into plates. The best results of breakage are reached at use of benzene that has zero molecule polarity and the best wettability of graphite surface. At ultra-sound dispersion in all environments, plane graphite particles are received that are several dozens of nano-meters thick. However, some particles broken in ultra-sound have visible fluctuations from ideal plane form and can form complicated spatial figures of irregular structure. The received results may be a base for creation of a method for receiving of thin graphite plates with geometrical parameters that are necessary for making of composites and objects of nano-techniques.

\section{References}

[1] M.Yu. Belova. Review article of LLC "Silur" specialists dedicated to intercalated and thermally expanded graphite (IG and TEG). -http://www.sealur.ru/pdf/useful/reports/grafit.pdf

[2] Shibaev A.A., Timofeeva A.A., Yusin S.I. Research of ultra-sound fluctuation influence on thermally expanded graphite. XX International Scientific and Practical Conference "Modern Technique and Technologies". 2011. P.349-350. (russian)

[3] Chemist's and Technologist's Guide http://chemanalytica.com/book/novyy_spravochnik_khimika_i_tekhnologa/12_obshchie_svedeniya/6106

[4] Electronic Guide - http://www.chemport.ru/data/data24.shtml

[5] A.T. Dideykin, V.V. Sokolov, D.A. Sakseev and al. Free graphene films from thermally expanded graphite. Journal of Technical Phisics. 2010. Vol.80. No.9. P.146-149. (russian) 
PECULIARITIES OF ULTRA-SOUND DISPERSION OF THERMALLY EXPANDED GRAPHITE

[6] B.A. Agranat, A.P. Gudovich, L.B. Nezhevenko. Ultra-sound in powder metallurgy. Moscow: Metallurgy. 1986. 168p. (russian)

[7] E.I. Zhmurikov. Research of Structure and Features of Graphite Composites for Convertor of Neutron Target. Paper ... candidate of sciences in Physics and Mathematics: 01.04.07. Zhmurikov Evgeniy Izotovich. Tomsk. 2010. 137p. (russian) 